\title{
Contemporary outcomes of surgery for aortic root aneurysms: A propensity-matched comparison of valve-sparing and composite valve graft replacement
}

\author{
Mario Gaudino, MD, Christopher Lau, MD, Monica Munjal, MS, Dimitrios Avgerinos, MD, and \\ Leonard N. Girardi, MD
}

\begin{abstract}
Objective: The study objective was to give an overview of the current state of the art of the surgical treatment of aortic root pathologies in a high-volume center.

Methods: From May 1997 to January 2014, aortic root replacement was performed in 890 consecutive patients; 289 received a mechanical composite valved graft, 421 received a biologic composite valved graft, and 180 received a valve-sparing reconstruction. Propensity matching analysis was used to neutralize the differences in baseline characteristics between patients assigned to the different procedures.
\end{abstract}

Results: Operative mortality was $0.2 \%(0 \%$ in the valve-sparing reconstruction group); the incidence of major postoperative complications was less than $0.5 \%$. Predictors of adverse in-hospital outcome were age, nonelective operation, renal status, reoperation, New York Heart Association class, ejection fraction, and concomitant procedures. Five-year survival was $89.4 \%$. Previous myocardial infarction, preoperative renal status, redo operation, and concomitant procedures were significantly associated with follow-up death. In the propensity-matched groups, the type of operation performed did not affect in-hospital and late outcome. Aortic reintervention rates at 5 years were $0 \%$ for the mechanical composite valved graft group, $2.4 \%$ for the biologic composite valved graft group, and $7.3 \%$ for the valve-sparing reconstruction series.

Conclusions: In the current era, aortic root replacement can be performed with low perioperative risk in high-volume aortic centers. The type of operation performed does not affect early or late survival. Although the mechanical composite valved graft remains the gold standard for durability, the biologic composite valved graft and valve-sparing reconstruction are excellent options for those who cannot take or want to avoid long-term anticoagulation. (J Thorac Cardiovasc Surg 2015;150:1120-9)

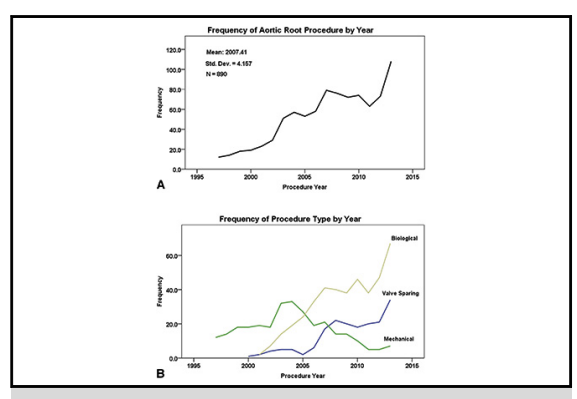

Temporal trends in aortic root surgery.

\section{Central Message}

Among 890 consecutive patients who underwent composite root replacement or a valve-sparing procedure, the type of operation performed did not affect early and late outcomes.

\section{Perspective}

This series shows how ARR can be performed in the current era with low operative risk and excellent long-term results, independently of the type of operation performed. The operation should be individualized to the characteristics and the need of the single patient.

See Editorial Commentary page 1130.

See Editorial page 1026.
Supplemental material is available online.

Surgery of the aortic root has changed substantially over the last 3 decades. For many years, the classic Bentall

From the Department of Cardiothoracic Surgery, Weill Cornell Medical College, New York, NY.

Received for publication March 23, 2015; revisions received June 22, 2015; accepted for publication July 4, 2015; available ahead of print July 31, 2015.

Address for reprints: Leonard N. Girardi, MD, Department of Cardiothoracic Surgery, Weill Cornell Medical College, 525 E 68th St, Suite M404, New York, NY 10065 (E-mail: lngirard@med.cornell.edu).

0022-5223/\$36.00

Copyright (c) 2015 by The American Association for Thoracic Surgery

http://dx.doi.org/10.1016/j.jtcvs.2015.07.015 operation was the only possible surgical solution for diseases involving the sinuses of Valsalva and the aortic valve. ${ }^{1}$ Even in experienced hands, the perioperative mortality was not insignificant. ${ }^{2-4}$ However, since the introduction of the exclusion technique, ${ }^{5}$ the mortality and major morbidity of aortic root replacement (ARR) have seen a dramatic decline. In recent years, groups focused on aortic disease have reported elective operative mortality less than $5 \%$, with a marked decline in the incidence of stroke, hemorrhage, and other major postoperative complications. ${ }^{6}$

Valve-sparing replacement (VSR) has introduced yet another modification to the surgical technique, allowing patients the opportunity for aortic root reconstruction while retaining their native aortic valve. ${ }^{7}$ In addition, 

Abbreviations and Acronyms
$\mathrm{ARR}=$ aortic root replacement
$\mathrm{bCVG}=$ biologic composite valved graft
$\mathrm{CTD}=$ connective tissue disorder
MAE $=$ major adverse event
$\mathrm{mCVG}=$ mechanical composite valved graft
NYHA $=$ New York Heart Association
PSM = propensity score matching
STS = Society of Thoracic Surgeons
VSR = valve-sparing replacement

improved durability of biological aortic valve replacement also has allowed patients in need of complete root replacement the option of a composite valve graft without the need for anticoagulation. ${ }^{8}$ These refinements in surgical technique, along with improvements in critical care, have dramatically improved the expectations for patients in need of ARR. A substantial decline in perioperative risk, together with a deeper understanding of the natural history and intrinsic mechanisms of aortic disease, has expanded the pool of patients in need of root surgery and exponentially increased the number of procedures performed over the last decade. ${ }^{6}$

To date, there has been limited comparison regarding which technique of ARR would be best for a variety of patient populations. Most of the data in these studies have been confounded by major selection bias or a limited number of patients for comparison. In an effort to better characterize the current state of ARR in a high-volume aortic center, we compared the results of 3 different contemporary surgical techniques: VSR, biologic composite valved graft (bCVG), and mechanical composite valved graft (mCVG) replacement. By using propensity score matching (PSM), we wanted to redefine expected outcomes for these complex procedures and identify factors that contribute negatively to both perioperative and long-term survival. Data generated from this analysis could be used to determine the most appropriate surgical option for a wide-ranging cohort of patients in need of ARR.

\section{MATERIALS AND METHODS}

\section{Patient Population and End Points}

This study was approved by the institutional review board. The need for individual patient consent was waived. A review of prospectively collected data from the Weill Cornell Medical College Department of Cardiothoracic Surgery aortic surgery database was conducted to identify all consecutive patients who underwent ARR from May 1997 to January 2014.

Overall, 1001 cases were identified; patients undergoing ARR for acute or chronic aortic dissection $(\mathrm{n}=111)$ were excluded from the analysis. Patients with extensive aortic root destruction because of aortic root infection were also excluded. Of the 890 remaining patients, 289 received an $\mathrm{mCVG}$, 421 received a bCVG, and 180 received VSR using the remodeling (9) $(\mathrm{n}=22)$ or reimplantation $(7)(\mathrm{n}=158)$ technique.
Primary end points were operative mortality and follow-up death from any cause. Secondary end points were the incidence of major postoperative complications (myocardial infarction, stroke, new-onset renal insufficiency requiring dialysis, need for tracheostomy, or deep sternal wound infection) and a composite of major adverse events (MAEs) postoperatively (inhospital death and major postoperative complications).

\section{Surgical Technique}

Indications for the operations were related to the severity of the valvular dysfunction or the size of aortic dilatation on the basis of best practice or the American Heart Association/American College of Cardiology guidelines. The operative technique used has been described in detail. ${ }^{9}$

Briefly, all the operations were performed using median sternotomy, central aortic cannulation, hypothermic cardiopulmonary bypass, aortic crossclamping, and myocardial protection with cold antegrade blood cardioplegia; $\varepsilon$-aminocaproic acid ( $5 \mathrm{~g}$ load and then $1 \mathrm{mg} / \mathrm{h}$ during bypass) was routinely used as an antifibrinolytic agent. In cases of concomitant disease in the aortic arch, deep hypothermic circulatory arrest with retrograde cerebral perfusion was used. ${ }^{10}$ ARR using an mCVG or a bCVG was performed using the modified Bentall technique. ${ }^{5}$ For patients in need of a biological prosthesis, the stented valve was sewn inside a Dacron prosthesis (Maquet Corp, Fairfield, NJ) 3 to $5 \mathrm{~mm}$ larger than the valve using a continuous 3-0 polypropylene suture. For VSR, the first 22 patients were treated using the Yacoub remodeling technique, ${ }^{11}$ whereas in the remaining 158 patients the classic David-I reimplantation method was used.

\section{Database, Follow-up, and Data Collection}

The Weill Cornell Medical College Department of Cardiothoracic Surgery aortic surgery database is constantly updated and maintained by a team of clinical information analysts; data collection is validated regularly by means of external and internal control. Preoperative and perioperative variables are entered prospectively during in-hospital stay. Postoperatively, clinical and computed tomography evaluation is performed after 6 months and every year thereafter or in case of clinical symptoms suggestive of aortic disease, and data are entered at the time of the follow-up visit. In case of missing or unreliable data, direct interview with the patient, a relative, or the treating physician is performed.

Follow-up was $90 \%$ complete. Median follow-up time was 22.0 months (25th percentile, 5.0 months; 75 th percentile, 52.5 months). Age- and sex-matched reference population survival estimates were obtained from the Centers for Disease Control and Prevention's National Vital Statistics Reports. Postoperative stroke was defined as the postoperative onset of a major neurologic deficit lasting more than 24 hours and accompanied by computed tomography evidence of ischemic or hemorrhagic brain lesion.

\section{Statistical Analysis}

Data were stored using Microsoft Access 2010 software (Microsoft Corp, Redmond, Wash) and analyzed using IBM SPSS Statistics version 22 (IBM, Armonk, NY), R version 3.2.0 (R Foundation for Statistical Computing), IBM SPSS Statistics-Essentials for R 22.0, cmprsk package, and MatchIt package.

Data from the study population were compared using the chi-square test for categoric variables and the Student $t$ test for continuous variables. Multivariate and univariate analyses for in-hospital MAE and long-term survival were computed to assess for significant demographic and preoperative predictors of such events.

Because of the heterogeneity in patient characteristics among the mCVG, bCVG, and VSR groups, PSM was used to adjust for baseline differences and reduce confounding. ${ }^{12,13}$ Three separate PSM models were built to compare the 3 surgical groups. The probability of being assigned to different surgical treatment was calculated from demographic and 

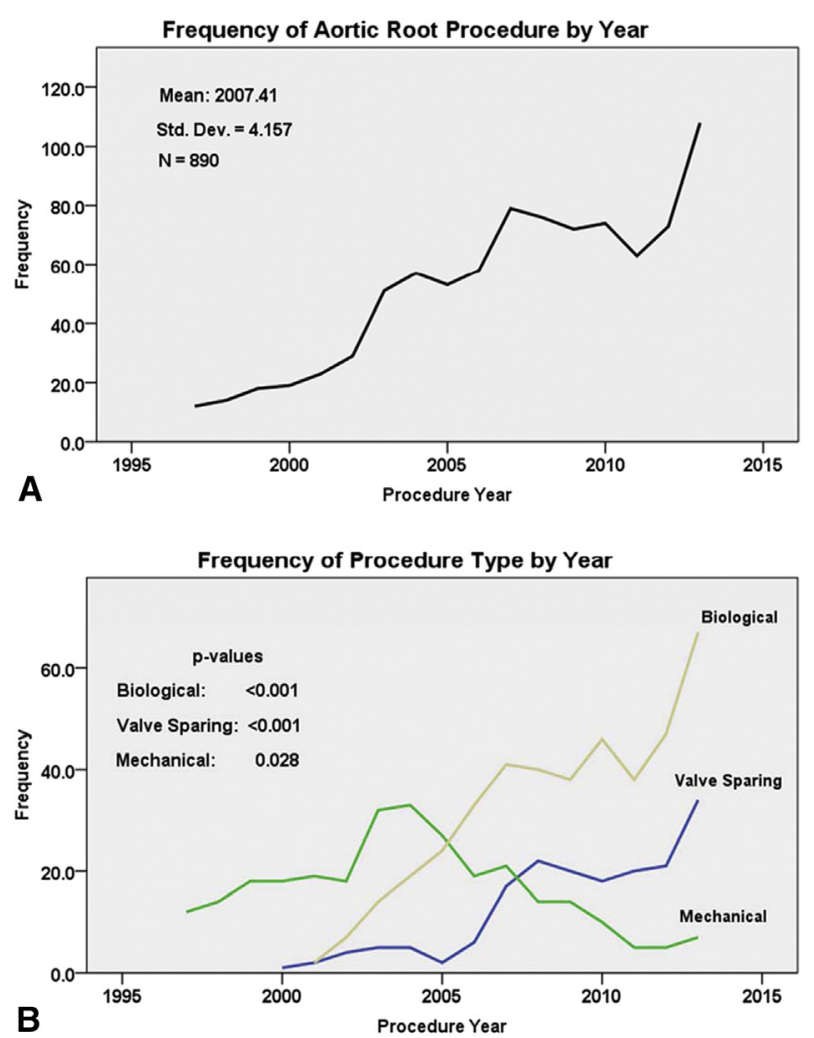

FIGURE 1. Temporal trends in the overall number of aortic root procedures (A) and by type of operation (B). Std. Dev., Standard deviation.

preoperative patients' characteristics; the most clinically important variables were then entered in the PSM model. Propensity scores were generated to be semi-saturated. Selected variables were age, family history, preoperative aneurysm status, diabetes, left ventricular ejection fraction, urgent/emergency procedure, hypertension, connective tissue disorders (CTDs), New York Heart Association (NYHA) class, previous aneurysm, preoperative renal status, previous myocardial infarction, previous open surgery, previous revascularization, and smoking. These covariates were used to compare the 3 surgical techniques by logistic regression algorithm in 1-1 PSM. Nearest neighbor matching algorithm without replacement and a caliper size of 0.05 was used. Propensity matching models were assessed using balance diagnostics and standardized differences and were confirmed by propensity score histograms with kernel density estimates. Linear regression was used to detect changes in frequency of procedures over time.

Postoperative survival was assessed using the Kaplan-Meier method. Censoring of patients occurred at the time of their last follow-up. Survivals of different surgical technique groups were compared in pairs by way of log-rank analysis. Survival comparison with an age- and sex-matched cohort was generated by way of the 1-sample log-rank test and KaplanMeier analysis tailored for such comparisons.

Actuarial methods were used to illustrate the proportion of reintervention. The Gray test was used to compare competing risk across groups, and cumulative incidence functions were generated using Fine and Gray methodology.

\section{RESULTS}

\section{Overall Population}

During the study period, there was a more than 5-fold increase in the annual number of aortic root operations performed; this was accompanied by a pronounced change in the relative percentages of the different procedures, with a progressive increase in the number of bCVGs and VSRs performed and a substantial reduction of $\mathrm{mCVG}$ (Figure 1).

Preoperative variables of the entire cohort of patients are summarized in Table 1 . The majority of patients were male in the sixth decade; smoking and hypertension were the predominant vascular risk factors, 112 patients $(12.6 \%)$ had CTD, and 351 patients $(39.4 \%)$ had bicuspid aortic valve. A total of 684 patients $(76.9 \%)$ were in NYHA class I/II, 783 patients $(87.9 \%)$ underwent the operation on an elective basis, and the mean preoperative left ventricular function was $46.7 \% \pm 8.5 \% ; 105$ patients $(11.8 \%)$ had previous cardiac surgery, and 148 patients $(16.6 \%)$ had a coexisting aortic arch aneurysm. Seven patients $(0.7 \% ; 4$ in the $\mathrm{mCVG}$ and 3 in the bCVG group) had active aortic valve endocarditis.

At surgery, 332 patients (37.3\%) underwent at least 1 associated cardiac procedure; the most frequent associated cardiac procedures were arch replacement (149 cases, 16.7\%) and coronary artery bypass (81 cases, $9.1 \%) ; 84$ cases $(9.4 \%)$ had more than 1 associated procedure (Table 2). Mean cardiopulmonary bypass and crossclamp times for isolated root replacement without concomitant procedures were $121.5 \pm 24$ minutes and $99.3 \pm 21$ minutes, respectively. Cystic medionecrosis was the most common pathologic finding (Table 2).

Overall operative mortality was $0.2 \%$ (2/890). The causes of death were respiratory insufficiency in 1 patient and malignant ventricular arrhythmia in 1 patient. Of note, the 2 deaths occurred in the first 5 years of the study period, whereas no death occurred among the 804 consecutive patients undergoing operation from 2002 to 2014. The incidences of stroke, myocardial infarction, and deep sternal wound infection were $0.5 \%, 0.1 \%$, and $0.1 \%$, respectively (Table 3 ). A total of 100 patients $(11.2 \%)$ received at least 1 blood transfusion, and mean red blood cell transfusion was $2.2 \pm 1.7$ units per patient.

Three- and 5-year survival were $94.8 \%$ and $89.4 \%$, respectively (Figure 2). Twenty patients $(2.2 \%)$ underwent reoperation on the aortic valve at a mean interval from the initial surgery of $71.7 \pm 47.3$ months. Cumulative incidence of aortic reintervention is depicted in Figure 3.

At multivariate analysis age, urgent/emergency operation, preoperative renal status, redo operation, NYHA class, preoperative ejection fraction, and need for associated procedures were significant predictors for the occurrence of MAE, whereas previous myocardial infarction, preoperative renal status, redo operation, and concomitant procedures were significantly associated with follow-up death (Table 4). 
TABLE 1. Preoperative characteristics in the overall unmatched population

\begin{tabular}{|c|c|c|c|c|}
\hline & Total population & bVC & mVC & VSR \\
\hline No. of cases & 890 & $421(47.3 \%)$ & $289(32.4 \%)$ & $180(20.2 \%)$ \\
\hline Male & $764(85.5 \%)$ & $367(87.4 \%)$ & $250(86.8 \%)$ & $147(81.2 \%)$ \\
\hline Age (y) & $55.3 \pm 14.5$ & $61.5 \pm 12.3 \dagger$ & $50.4 \pm 13.5 \dagger$ & $48.8 \pm 14.9$ \\
\hline Smoking & $291(32.7 \%)$ & $142(33.7 \%)$ & $111(38.4 \%) \dagger$ & $38(21.1 \%)$ \\
\hline Previous coronary revascularization $\dagger$ & $35(3.9 \%)$ & $28(6.7 \%)^{*}, \dagger$ & $6(2.1 \%)$ & $1(0.6 \%)$ \\
\hline Hypertension & $727(81.7 \%)$ & $386(91.7 \%)^{*}, \dagger$ & $225(77.9 \%) \dagger$ & $116(64.4 \%)$ \\
\hline Chronic lung disease & $43(4.8 \%)$ & $24(5.7 \%) \dagger$ & $17(5.9 \%) \dagger$ & $2(1.1 \%)$ \\
\hline Previous myocardial infarction & $55(6.2 \%)$ & $38(9.0 \%)^{*}, \dagger$ & $15(5.2 \%)$ & $2(1.1 \%)$ \\
\hline Stroke & $49(5.5 \%)$ & $24(5.7 \%)$ & $17(5.9 \%)$ & $8(4.4 \%)$ \\
\hline Peripheral vascular disease & $22(2.5 \%)$ & $12(2.9 \%)$ & $6(2 \%)$ & $4(2.2 \%)$ \\
\hline Diabetes & $29(3.3 \%)$ & $19(4.5 \%)$ & $6(2.1 \%)$ & $4(2.2 \%)$ \\
\hline Creatinine $>1.5 \mathrm{mg} / \mathrm{dL}$ & $39(4.4 \%)$ & $21(5 \%) \dagger$ & $18(6.2 \%) \dagger$ & 0 \\
\hline Dialysis & $7(0.8 \%)$ & $3(0.7 \%)$ & $2(0.7 \%)$ & $2(1.1 \%)$ \\
\hline NYHA class I/II & $684(76.9 \%)$ & $289(68.7 \%)^{*}, \dagger$ & $228(78.9 \%) \dagger$ & $167(92.8 \%)$ \\
\hline Left ventricular ejection fraction & $46.7 \pm 8.5$ & $46.7 \pm 8.5^{*}, \dagger$ & $45.1 \pm 9 \dagger$ & $51.9 \pm 6.4$ \\
\hline CTDs & $113(12.6 \%)$ & $13(3.1 \%)^{*}, \dagger$ & $54(18.6 \%)$ & $46(25.6 \%)$ \\
\hline Bicuspid aortic valve & $351(39.4 \%)$ & $217(51.5 \%) \dagger$ & $88(30.4 \%) \dagger$ & $46(25.6 \%)$ \\
\hline Family history of aneurysm & $89(10 \%)$ & $19(4.5 \%)^{*}, \dagger$ & $29(10 \%) \dagger$ & $41(22.8 \%)$ \\
\hline Urgent/emergency procedure & $107(12 \%)$ & $32(7.7 \%)^{*}$ & $66(22.9 \%) \dagger$ & $9(5 \%)$ \\
\hline Previous cardiac surgery & $105(11.8 \%)$ & $40(9.5 \%)^{*}$ & $59(20.5 \%) \dagger$ & $6(3.3 \%)$ \\
\hline \multicolumn{5}{|l|}{ Associated aneurysms } \\
\hline - Aortic arch & $148(16.6 \%)$ & $81(19.3 \%) \dagger$ & $53(18.3 \%) \dagger$ & $14(7.7 \%)$ \\
\hline - Descending aorta & $1(0.1 \%)$ & 0 & $1(0.3 \%)$ & 0 \\
\hline - Abdominal aorta & $4(0.4 \%)$ & $3(0.7 \%)$ & $1(0.3 \%)$ & 0 \\
\hline - Thoracoabdominal aorta & $8(0.9 \%)$ & $3(0.7 \%)$ & $2(0.7 \%)$ & $3(1.7 \%)$ \\
\hline - Coronary arteries & $1(0.1 \%)$ & 0 & $1(0.3 \%)$ & 0 \\
\hline \multicolumn{5}{|l|}{ Aortic valve status } \\
\hline - Stenosis & $114(12.8 \%)$ & $82(19.5 \%)^{*}, \dagger$ & $32(11.1 \%) \dagger$ & 0 \\
\hline - Insufficiency & $756(84.9 \%)$ & $333(79.1 \%)^{*}, \dagger$ & $257(88.9 \%) \dagger$ & $166(92.2 \%)$ \\
\hline
\end{tabular}

$b V C$, Biological valved conduit; $C T D$, connective tissue disorder; $m V C$, mechanical valved conduit; NYHA, New York Heart Association; VSR, valve-sparing replacement. $* P<.05$ versus $\mathrm{mVC} . \dagger P<.05$ versus VSR.

\section{Comparison of the Outcomes of Different Surgical Procedures}

In the unmatched population, patients receiving a bCVG were older and had more comorbidities and worse functional class than patients undergoing $\mathrm{mCVG}$ or VSR (Table 1). Redo procedures and urgent/emergency operations were more common in the mCVG series, whereas CTD was more common in the VSR group. Patients receiving bCVG or $\mathrm{mCVG}$ were more likely to have coexisting aneurysms of the aortic arch that required circulatory arrest for repair (Table 2). Associated cardiac procedures were also more frequently performed in the bCVG and mCVG cases (Table 2).

Propensity matching analysis was used to neutralize the differences in baseline characteristics among patients assigned to the 3 different types of operation (Table 5 and

TABLE 2. Intraoperative data in the overall unmatched population

\begin{tabular}{|c|c|c|c|c|}
\hline & Total population & bVC & $\mathbf{m V C}$ & VSR \\
\hline No. of cases & 890 & 421 & 289 & 180 \\
\hline Concomitant procedures & $332(37.3 \%)$ & $176(41.8 \%)^{*}, \dagger$ & $110(38.0 \%) \dagger$ & $46(25.5 \%)$ \\
\hline$>1$ concomitant procedures & $84(9.4 \%)$ & $40(9.5 \%)$ & $30(10.4 \%)$ & $14(7.7 \%)$ \\
\hline CPB time $(\min ) \dagger$ & $121.5 \pm 24.1$ & $113.2 \pm 21.3^{*}, \dagger$ & $126.6 \pm 26.8 \dagger$ & $130.2 \pm 20$ \\
\hline Crossclamp time $(\min ) \dagger$ & $99.3 \pm 21.6$ & $91.2 \pm 19.4$ & $102.4 \pm 21.7 \dagger$ & $109.9 \pm 19.9$ \\
\hline Circulatory arrest & $154(17.3 \%)$ & $83(19.7 \%) \dagger$ & $56(19.4 \%) \dagger$ & $15(8.3 \%)$ \\
\hline Graft size $(\mathrm{mm})$ & $26.5 \pm 2.6$ & $25.5 \pm 1.9^{*}, \dagger$ & $26.0 \pm 2.6 \dagger$ & $29.5 \pm 1.2$ \\
\hline \multicolumn{5}{|l|}{ Histologic findings } \\
\hline - Atherosclerosis & $78(8.8 \%)$ & $64(19.5 \%)^{*}, \dagger$ & $7(8.5 \%)$ & $7(4.4 \%)$ \\
\hline - Cystic medio-necrosis & $478(53.7 \%)$ & $260(79.3 \%)^{*}, \dagger$ & $70(85.4 \%)$ & $148(93.7 \%)$ \\
\hline
\end{tabular}

$b V C$, Biological valved conduit; $C P B$, cardiopulmonary bypass; $m V C$, mechanical valved conduit; $V S R$, valve-sparing replacement. $* P<.05$ versus mVC. $\dagger P<.05$ versus VSR. 
TABLE 3. Postoperative course in the overall unmatched population

\begin{tabular}{|c|c|c|c|c|}
\hline & Total population & bVC & $\mathbf{m V C}$ & VSR \\
\hline No. of cases & 890 & 421 & 289 & 180 \\
\hline In-hospital death & $2(0.2 \%)$ & $1(0.2 \%)$ & $1(0.3 \%)$ & 0 \\
\hline Myocardial infarction & $1(0.1 \%)$ & 0 & $1(0.3 \%)$ & 0 \\
\hline Stroke & $5(0.5 \%)$ & $4(1.1 \%)$ & $1(0.3 \%)$ & 0 \\
\hline Need for tracheostomy & $4(0.4 \%)$ & $2(0.5 \%)$ & $2(0.7 \%)$ & 0 \\
\hline Postoperative dialysis & $5(0.5 \%)$ & $3(0.7 \%)$ & $1(0.3 \%)$ & $1(0.6 \%)$ \\
\hline Reexploration for bleeding & $31(3.5 \%)$ & $15(3.6 \%)$ & $9(3.1 \%)$ & $7(3.9 \%)$ \\
\hline Deep sternal wound infection & $1(0.1 \%)$ & $1(0.2 \%)$ & 0 & 0 \\
\hline Chest tube drainage $(\mathrm{mL} / 24 \mathrm{~h})$ & $497.7 \pm 282.4$ & $511.7 \pm 216.2$ & $488.4 \pm 369.0$ & $480.0 \pm 258.8$ \\
\hline No. of patients requiring $\mathrm{RBC}$ transfusion & $100(11.2 \%)$ & $43(10.2 \%)$ & $51(17.6 \%)$ & $6(3.3 \%)$ \\
\hline Units of PRBC transfused & $2.2 \pm 1.7$ & $2.0 \pm 1.3$ & $2.4 \pm 2.0$ & $1.8 \pm 0.4$ \\
\hline Postoperative MAE & $18(2.0 \%)$ & $11(2.7 \%)$ & $6(1.9 \%)$ & $1(0.6 \%)$ \\
\hline
\end{tabular}

$b V C$, Biological valved conduit; $M A E$, major adverse event; $m V C$, mechanical valved conduit; $P R B C$, packed red blood cells; $R B C$, red blood cell; VSR, valve-sparing replacement.

Figure E1). In-hospital outcome was similar for the $\mathrm{mCVG}$, bCVG, and VSR cases in the overall and in the propensitymatched population (Tables 3 and 6). Of note, there was no perioperative mortality in the VSR group.

Median follow-up time was longer for the $\mathrm{mCVG}$ group (47 months vs 16 months for bCVG and 16 months for VSR, $P<.0001)$. After propensity matching, the follow-up time was significantly different only for the VSR versus mCVG comparison (median 12 vs 30 months, $P<.001)$.

In the unmatched population, long-term survival was comparable for the $\mathrm{mCVG}$ and bCVG groups and significantly better for the VSR group (Figure 2). However, in the propensity-matched comparison, the long-term outcome was similar independently of the type of operation performed, and the survival advantage of patients in the VSR group was not evident (Figure 4).

During the follow-up, 2 patients of the mCVG series, 13 patients of the bCVG series, and 5 patients of the VSR series underwent reoperation on the aortic valve $(0.6 \%, 3.0 \%$, and $2.7 \%$, respectively, $P<.001$ for the comparison between $\mathrm{mCVG}$ and both $\mathrm{bCVG}$ and VSR, $P=.60$ for the comparison between $\mathrm{bCVG}$ and VSR). Aortic reintervention rates at 5 years was $0 \%$ for the $\mathrm{mCVG}$ group, $2.4 \%$ for the bCVG group, and $7.3 \%$ for the VSR group (Figure 3). In the VSR group, the rate of reoperation was significantly higher among patients submitted to the remodeling versus the reimplantation technique (3/22 vs $2 / 158$, $P<.001)$. When limiting the analysis to patients submitted to the David operation, the difference between the VSR and mCVG series becomes nonsignificant (2/158 vs $2 / 289$, $P=.63)$.

\section{DISCUSSION}

The surgical treatment of aortic root pathology has undergone fundamental change. Barely a decade ago, total replacement of the aortic valve and root using an $\mathrm{mCVG}$ was the primary surgical option for disease in the proximal portion of the aorta. ${ }^{2-4}$ Postoperative mortality ranged from $4 \%$ to $8 \% .^{2-4}$ In recent years, refinement in surgical techniques and critical care management has significantly reduced the operative risk, allowing older and sicker patients the option of treatment for significant aortic root pathology. Simultaneously, the introduction of valve-sparing operations and a better understanding of the pathophysiology and natural history of aortic root disease led to the concept of "prophylactic" surgery and a further extension of these complex procedures to a younger and healthier population of patients. Although VSR has proven to be an excellent option for these younger patients, the complexity of the procedure with its longer crossclamp and bypass times, as well as the potential for needing reoperation for valve failure, left older and sicker patients with $\mathrm{mCVG}$ as their best alternative. This mainstay of ARR for decades certainly could be performed safely with excellent long-term durability, ${ }^{14}$ but it was a poor option for those wanting or needing to avoid anticoagulation. Fortunately, there has been a significant improvement in the durability of prosthetic biological valves. $^{8}$ This led to the increasing popularity of the bCVG as an alternative for higher-risk patients. ${ }^{15}$ These developments contributed heavily to the exponential increase in the number of ARR procedures performed. Data from the Society of Thoracic Surgeons (STS) Adult Cardiac Surgery Database showed a linear increase in proximal aortic surgery in the United States between 2004 and 2009. Aortic root operations now represent approximately $5 \%$ of all cardiac procedures performed in the nation. 6,15

Similar to that seen in the STS database, we also noted a 5-fold increase in the number of root replacements during the study period with a progressive shift away from a traditional $\mathrm{mCVG}$ operation in the early years to widespread adoption of the bCVG and VSR procedures in 

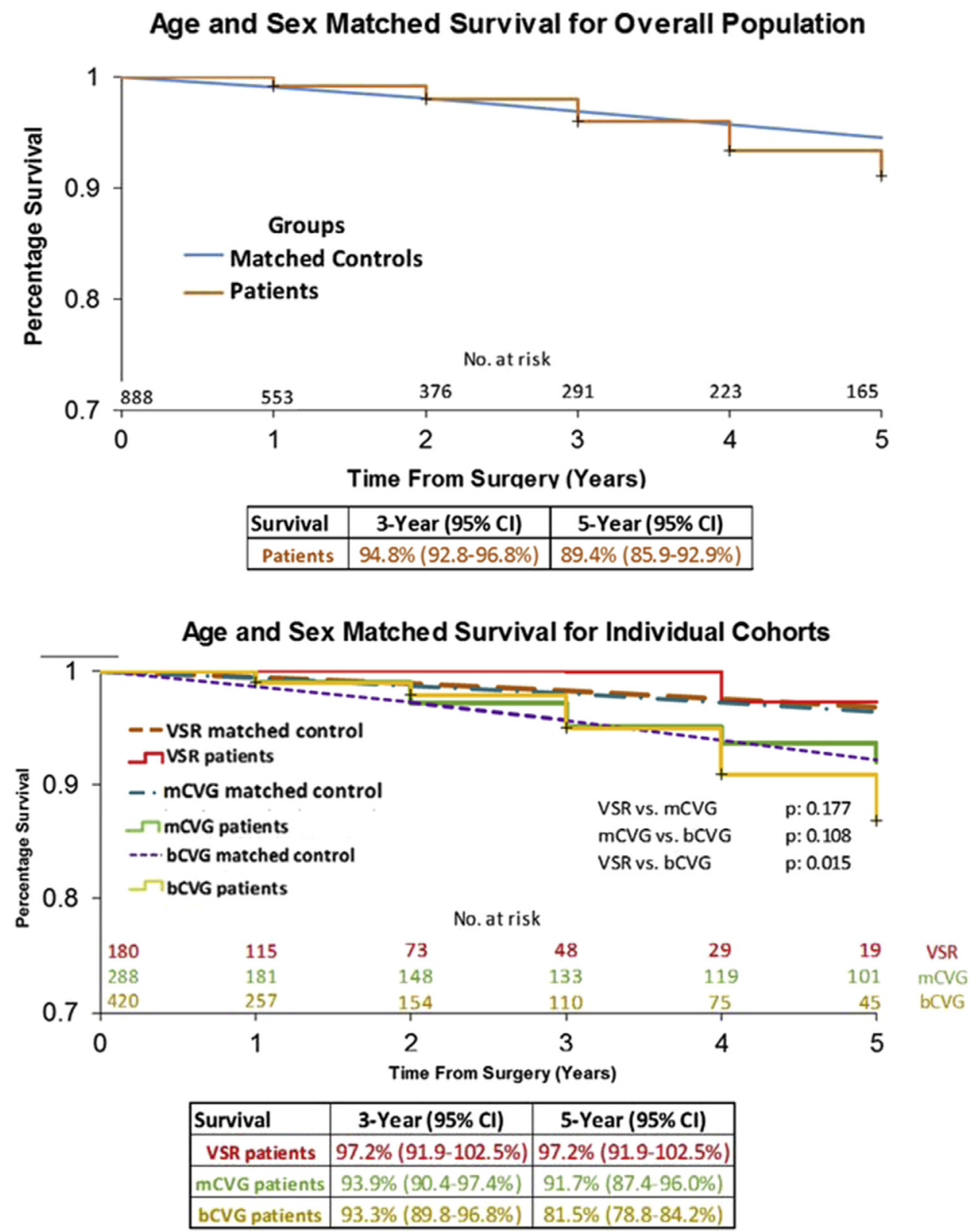

FIGURE 2. Kaplan-Meier survival curves overall and by type of operation in the unmatched population. $b C V G$, Biologic composite valved graft; $C I$, confidence interval; $m C V G$, mechanical composite valved graft; $V S R$, valve-sparing replacement.

the most recent period. However, to date there have been few direct comparisons of the early and long-term results of the different surgical techniques for ARR. Kallenbach and colleagues ${ }^{16}$ analyzed a series of 548 patients who underwent mCVG, supracoronary aortic replacement, or VSR. They were unable to show clinically meaningful differences in their early outcomes. ${ }^{16}$ Lim and coauthors ${ }^{17}$ reviewed a smaller experience comparing $72 \mathrm{mCVG}$ and 48 VSR procedures. They also found equivalent perioperative outcomes, survival, and intermediate-term valverelated complications. ${ }^{17}$ Zehr and associates ${ }^{2}$ confirmed these findings in a group of 203 cases, whereas Franke and colleagues ${ }^{18}$ comparing 76 VSR with $67 \mathrm{mCVG}$ cases found better hospital and 1- and 3-year survival, freedom from major events, and better quality of life for the former. Badiu and colleagues, ${ }^{19}$ in a series similar to ours, compared 370 patients who underwent VSR, $\mathrm{mCVG}$, and bCVG. They reported improved 5-year survival among patients undergoing VSR. ${ }^{19}$ Concordantly, a recent report from the STS Database on 31,747 patients also ascribed lower operative mortality for VSR procedures. ${ }^{20}$ 


\section{Reintervention After Surgery}

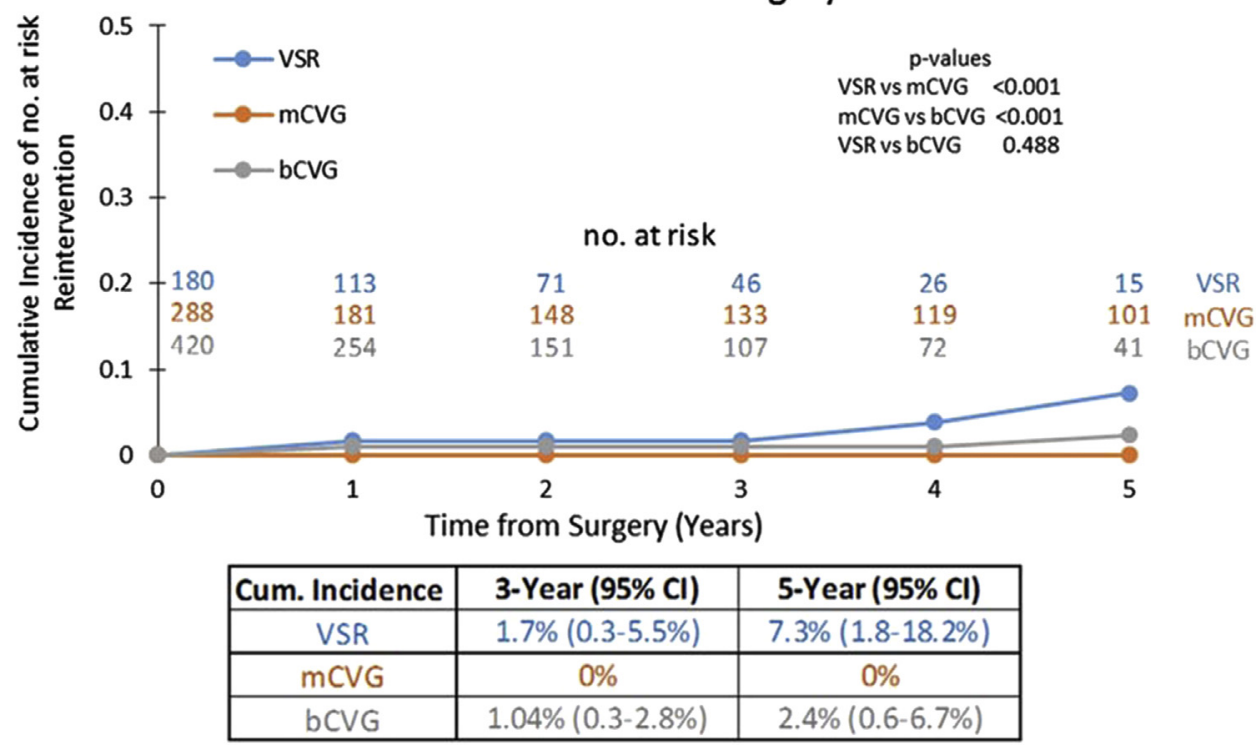

FIGURE 3. Cumulative incidence of aortic reintervention by type of operation in the unmatched population. $b C V G$, Biologic composite valved graft; $C I$, confidence interval; $m C V G$, mechanical composite valved graft; $V S R$, valve-sparing replacement.

Similar heterogeneity exists even when looking at the studies that compared mCVG and bCVG. Etz and colleagues ${ }^{21}$ found no difference in early or long-term survival. Freedom from reoperation was similar in 597 patients having 1 of these 2 techniques of CVG. Lehr and associates ${ }^{22}$ reported similar results in a smaller series of 144 cases, but Stamou and colleagues, ${ }^{15}$ in a recent review of data from the STS database including 13.473 cases, reported higher in-hospital mortality among patients undergoing bCVG. However, patients undergoing bCVG were older and had a higher incidence of hypertension, chronic lung disease, diabetes, and urgent operation, making intergroup comparison difficult.

TABLE 4. Predictors of in-hospital and follow-up events at multivariate analysis in the overall population

\begin{tabular}{lc}
\hline & $\boldsymbol{P}$ value \\
\hline In-hospital MAE: & $<.001$ \\
Age & .002 \\
Urgent/emergency operation & $<.001$ \\
Preoperative renal insufficiency & $<.001$ \\
Redo surgery & .03 \\
NYHA class & .02 \\
LVEF & $<.001$ \\
Associated procedures & \\
Follow-up death: & .03 \\
Previous MI & $<.001$ \\
Preoperative renal insufficiency & .02 \\
Redo surgery & .03 \\
Associated procedures & $<.001$ \\
Symptomatic aneurysm & \\
\hline
\end{tabular}

$\overline{L V E F \text {, Left ventricular ejection fraction; } M A E \text {, major adverse event; } M I \text {, myocardial }}$ infarction; NYHA, New York Heart Association.
In fact, all of the published studies suffer from major methodological limitations related to limited sample size or major differences in baseline risk profile of the patients assigned to the different surgical procedures. Significant heterogeneity in patient age and comorbidities contributed heavily to the disparities seen from respected surgical centers. Our analysis attempts to obviate the wide range in outcomes by applying propensity matching analysis to minimize confounding variables. By using this methodology, we found that the surgical technique used did not affect in-hospital mortality or long-term survival. In fact, although the analysis of data of the unmatched population suggested a longterm survival benefit for patients undergoing VSR, this advantage was mitigated when preoperative differences were corrected by propensity-matched comparison. The survival of patients treated by $\mathrm{mCVG}$, bCVG, and VSR was comparable perioperatively and at late follow-up. Operative mortality was $0.2 \%$ in the entire cohort and $0 \%$ in the VSR group, with no death occurring among the last 804 consecutive patients. These data reassure both patients and referring physicians of the safety of ARR performed in high-volume aortic centers in the modern era while also setting new standards for expected outcomes for what was once a somewhat delicate and unpredictable type of surgery.

In the past years, concerns have been expressed on the safety and durability of VSR procedures. However, excellent results have been reported recently even in a highrisk cohort of patients with Marfan syndrome. ${ }^{23,24}$ Our data clearly confirm the very low surgical risk and excellent long-term results of VSR with no in-hospital 
TABLE 5. Preoperative characteristics of the propensity-matched groups

\begin{tabular}{|c|c|c|c|c|c|c|c|c|c|}
\hline & VSR & mVC & $P$ & mVC & bVC & $P$ & VSR & bVC & $P$ \\
\hline No. of cases & 129 & 129 & & 152 & 152 & & 132 & 132 & \\
\hline Male & 109 & 113 & .47 & 131 & 131 & 1.0 & 110 & 115 & .38 \\
\hline Age (y) & $50.2 \pm 14.3$ & $47.8 \pm 12.4$ & .09 & $55.6 \pm 12.2$ & $54.7 \pm 13.1$ & .50 & $53.7 \pm 12.4$ & $53.3 \pm 12.9$ & .81 \\
\hline CAD & 1 & 0 & .3 & 4 & 1 & .17 & 1 & 1 & 1.0 \\
\hline Hypertension & 90 & 95 & .49 & 130 & 127 & .63 & 104 & 103 & .88 \\
\hline COPD & 2 & 4 & .40 & 11 & 10 & .82 & 2 & 3 & .65 \\
\hline Previous MI & 2 & 2 & 1.0 & 11 & 7 & .49 & 2 & 4 & .18 \\
\hline Stroke & 5 & 2 & .25 & 11 & 7 & .33 & 4 & 5 & .73 \\
\hline PVD & 4 & 3 & .70 & 5 & 4 & .73 & 2 & 2 & 1.0 \\
\hline Diabetes & 2 & 2 & 1.0 & 3 & 1 & .31 & 4 & 4 & 1.0 \\
\hline Creatinine $>1.5 \mathrm{mg} / \mathrm{dL}$ & 2 & 3 & .09 & 8 & 12 & .63 & 0 & 2 & .36 \\
\hline NYHA class III-IV & 13 & 9 & .24 & 33 & 32 & .94 & 2 & 0 & .25 \\
\hline Urgent/emergency & 9 & 6 & .51 & 20 & 16 & .53 & 6 & 7 & $\therefore$ \\
\hline LVEF \% & $49.9 \pm 5.8$ & $49.8 \pm 6.1$ & .15 & $46.2 \pm 8.6$ & $47.1 \pm 8.6$ & .39 & $51 \pm 6.3$ & $50.4 \pm 6.8$ & .4 \\
\hline
\end{tabular}

$\overline{b V C}$, Biological valved conduit; $C A D$, coronary artery disease; $C O P D$, chronic obstructive pulmonary disease; $L V E F$, left ventricular ejection fraction; $M I$, myocardial infarction; $m V C$, mechanical valved conduit; NYHA, New York Heart Association; PVD, peripheral vascular disease; VSR, valve-sparing replacement.

mortality or long-term deaths among the 158 patients submitted to the reimplantation procedure. Although the $\mathrm{mCVG}$ remains the gold standard in regard to durability, the high freedom from reoperation in the bCVG and VSR groups at midterm follow-up is extremely reassuring.

Of note, the incidence of reoperation in the VSR group was mainly determined by the high failure rate of the remodeling procedure. When limiting the analysis to patients submitted to the David operation, the difference between the VSR and $\mathrm{mCVG}$ series becomes nonsignificant $(2 / 158$ vs $2 / 289, P=.63$ ).

Moreover, our study was not designed to take into account late bleeding and thrombotic complications, and for this reason we were not able to demonstrate this important advantage of the non-mCVG procedures. These findings support a wider and more aggressive adoption of this operation, especially in view of the potential benefits of early surgery in terms of avoidance of aortic catastrophes, preservation of left ventricular function, and aortic leaflet integrity.

TABLE 6. Postoperative course in the propensity-matched groups

\begin{tabular}{lcccccccccc}
\hline & VSR & $\mathbf{m V C}$ & $\boldsymbol{P}$ & $\mathbf{m V C}$ & $\mathbf{b V C}$ & $\boldsymbol{P}$ & VSR & $\mathbf{b V C}$ & $\boldsymbol{P}$ \\
\hline In-hospital death & 0 & 0 & $\mathrm{NS}$ & 0 & 0 & $\mathrm{NS}$ & 0 & 1 & .31 \\
Myocardial infarction & 0 & 0 & $\mathrm{NS}$ & 0 & 0 & $\mathrm{NS}$ & 0 & 0 & $\mathrm{NS}$ \\
Stroke & 0 & 1 & .31 & 1 & 2 & .56 & 0 & 0 & $\mathrm{NS}$ \\
$\quad \begin{array}{l}\text { Need for } \\
\quad \text { tracheostomy }\end{array}$ & 0 & 0 & $\mathrm{NS}$ & 1 & 0 & .31 & 0 & 0 & $\mathrm{NS}$ \\
$\begin{array}{l}\text { Postoperative dialysis } \\
\text { Reexploration for }\end{array}$ & 1 & 0 & .31 & 0 & 0 & 1.0 & 1 & 2 & 1.0 \\
$\quad$ bleeding & 3 & 1.0 & 2 & 5 & .25 & 6 & 6 & 1.0 \\
$\begin{array}{l}\text { Deep sternal wound } \\
\quad \text { infection }\end{array}$ & 0 & 0 & $\mathrm{NS}$ & 0 & 1 & .36 & 0 & 1 & .31 \\
Postoperative MAE & 1 & 1 & $\mathrm{NS}$ & 2 & 3 & .65 & 1 & 4 & .17 \\
\hline
\end{tabular}

$b V C$, Biological valved conduit; $M A E$, major adverse event; $m V C$, mechanical valved conduit; NS, not significant; VSR, valve-sparing replacement.
For older patients or those with significant comorbidities, bCVG allows a rapid alternative ARR with a significant reduction in both aortic crossclamp time and time on cardiopulmonary bypass. Our data show that despite a significant increase in patient age, incidence of major risk factors and comorbidities (previous myocardial infarction, hypertension, chronic pulmonary disease, chronic renal insufficiency), worse functional status and ejection fraction, and higher incidence of urgent operation, patients undergoing bCVG can expect a durable long-term survival comparable to those younger and lower-risk patients undergoing $\mathrm{mCVG}$ but without the need for lifelong anticoagulation. bCVG seems to be the most appropriate technique for elderly patients and those with significant comorbid conditions who need a short procedure that may negate the perioperative complications often seen in patients requiring extensive periods of cardiopulmonary bypass to complete their operations.

\section{Study Limitations}

Our study obviously lacks the rigor and strength of a randomized controlled trial and reflects the experience of a single tertiary aortic center. However, all data were prospectively entered in the database by a team of clinical information analysts, data collection was validated regularly by means of external and internal control, the sample size is one of the largest published to date, and the propensitymatching method was used to minimize the potential confounding factors. ${ }^{12,13}$

\section{CONCLUSIONS}

In the current era, ARR can be performed in high-volume aortic centers with a low perioperative mortality and morbidity. The type of ARR does not affect outcomes. Long-term survival is equivalent in propensity-matched populations and mostly influenced by patient-related 
PS-Matched Survival: Valve Sparing vs. Mechanical

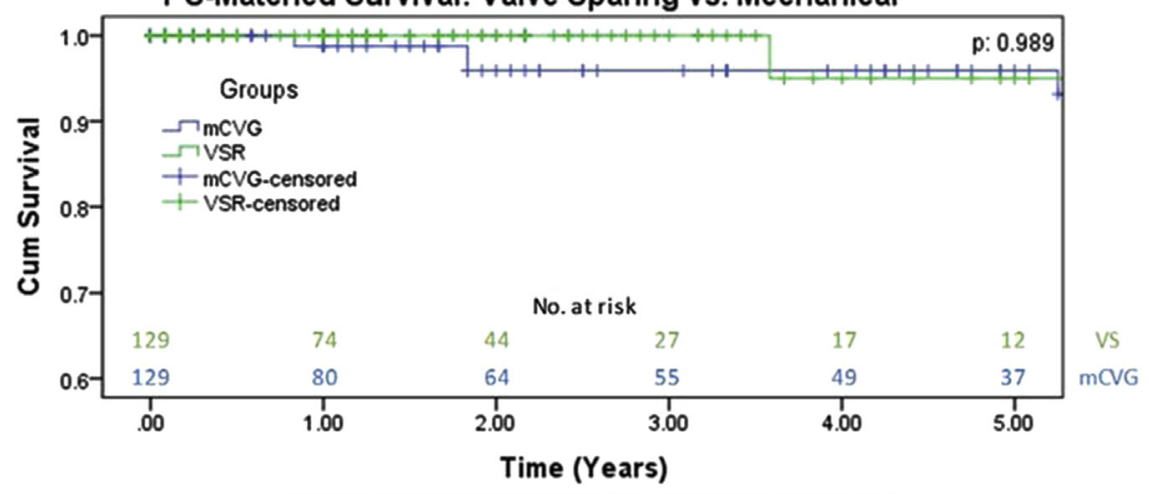

\begin{tabular}{|c|c|c|}
\hline Survival & 3-Year (95\% Cl) & 5-Year (95\% Cl) \\
\hline VSR & $100 \%$ & $95.0 \%(85.4-104.6 \%)$ \\
\hline mCVG & $95.9 \%(91.4-100.4 \%)$ & $95.9 \%(91.4-100.4 \%)$ \\
\hline
\end{tabular}

PS-Matched Survival: Mechanical vs. Biological

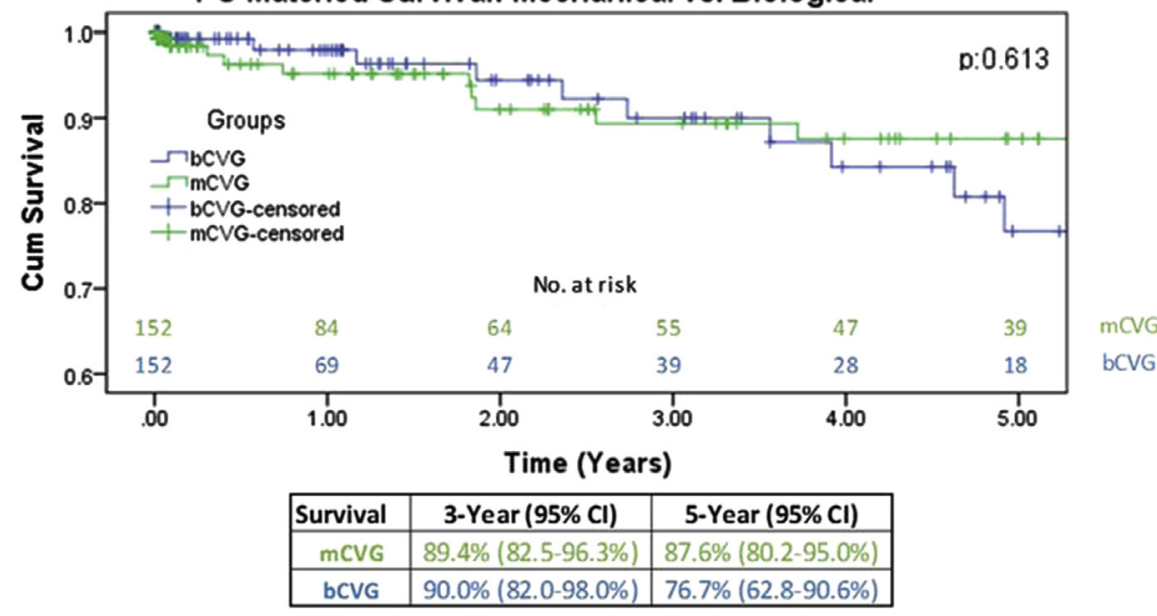

PS-Matched Survival: Valve Sparing vs. Biological

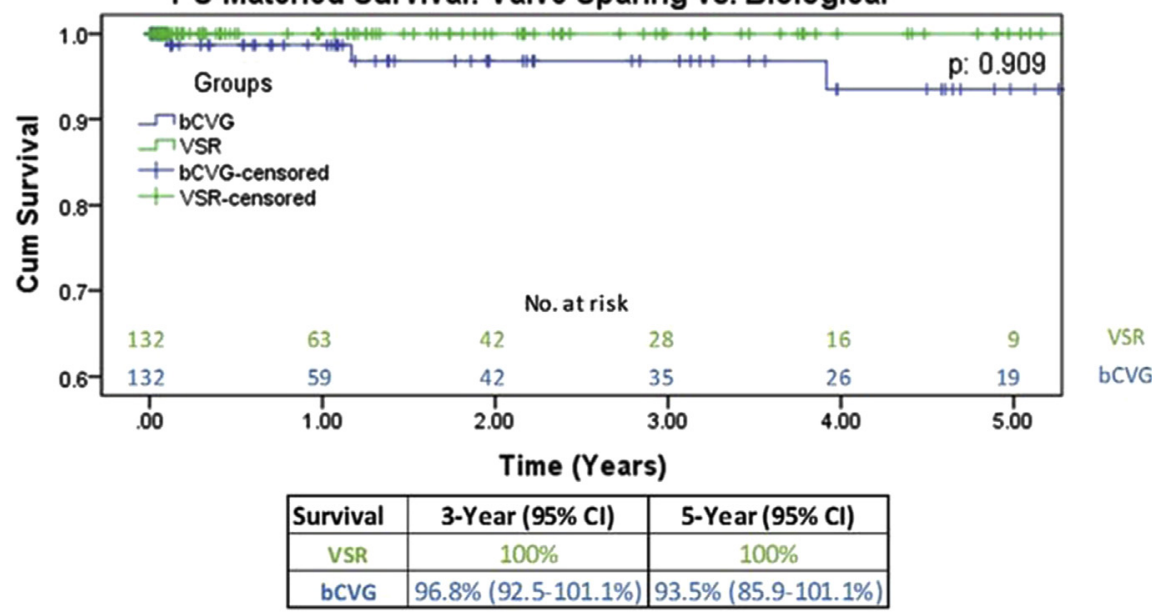

FIGURE 4. Kaplan-Meier survival curves by type of operation in the propensity-matched population. $b C V G$, Biologic composite valved graft; $C I$, confidence interval; $m C V G$, mechanical composite valved graft; $P S$, propensity score; VSR, valve-sparing replacement. 
characteristics rather than surgical technique. Surgeons with extensive experience in aortic surgery can tailor their choice of ARR to the procedure that best suits the individual patient on the basis of his/her baseline characteristics. VSR can be performed with minimal surgical risk and excellent freedom from valve-related complications and can be considered the primary option for ARR in younger and healthier patients. Extension to higher-risk cohorts, such as those with acute type A dissections, bicuspid aortic valves, and severe aortic insufficiency, can be expected as experience with this procedure grows.

bCVG is a reliable and reproducible option for older and sicker patients in need of an expeditious operation. Further refinements in technique, perioperative care, and prosthetic valve durability may allow ARR in an even greater number of the ever increasing percentage of elderly patients in our population. The $\mathrm{mCVG}$, the gold standard procedure for ARR in a previous era, remains a viable option that can be performed safely and efficiently with minimal risk. Perhaps as mechanical valve technology improves toward lesser amounts of or no anticoagulation, ${ }^{25}$ the number of mCVGs performed could again increase, restoring it as the most durable surgical option with the least risk for further valve-related surgery.

\section{Conflict of Interest Statement}

Authors have nothing to disclose with regard to commercial support.

\section{References}

1. Bentall H, De Bono A. A technique for complete replacement of the ascending aorta. Thorax. 1968;23:338-9.

2. Zehr KJ, Orszulak TA, Mullany CJ, Matloobi A, Daly RC, Dearani JA, et al. Surgery for aneurysms of the aortic root: a 30-year experience. Circulation. 2004;110:1364-71.

3. Mataraci I, Polat A, Kiran B, Calişkan A, Tuncer A, Erentug V, et al. Long-term results of aortic root replacement: 15 years' experience. Ann Thorac Surg. 2009; $87: 1783-8$

4. Etz CD, Bischoff MS, Bodian C, Roder F, Brenner R, Griepp RB, et al. The Bentall procedure: is it the gold standard? A series of 597 consecutive cases. J Thorac Cardiovasc Surg. 2010;140:S64-70.

5. Kouchoukos NT, Wareing TH, Murphy SF, Perrillo JB. Sixteen-year experience with aortic root replacement. Results of 172 operations. Ann Surg. 1991;214:308-18.

6. Williams JB, Peterson ED, Zhao Y, O'Brien SM, Andersen ND, Miller DC, et al. Contemporary results for proximal aortic replacement in North America. J Am Coll Cardiol. 2012;60:1156-62.

7. David TE, Feindel CM. An aortic valve-sparing operation for patients with aortic incompetence and aneurysm of the ascending aorta. J Thorac Cardiovasc Surg. 1992;103:617-22.
8. Chiang YP, Chikwe J, Moskowitz AJ, Itagaki S, Adams DH, Egorova NN Survival and long-term outcomes following bioprosthetic vs mechanical aortic valve replacement in patients aged 50 to 69 years. JAMA. 2014;312:1323-9.

9. Girardi LN. Composite root replacement with a mechanical conduit. Oper Tech Thorac Cardiovasc Surg. 2008;13:148-60.

10. Girardi LN, Shavladze N, Sedrakyan A, Neragi S. Safety and efficacy of retrograde cerebral perfusion as an adjunct for cerebral protection during surgery on the aortic arch. J Thorac Cardiovasc Surg. 2014;148:2927-33.

11. Sarsam MA, Yacoub M. Remodeling of the aortic valve annulus. J Thorac Cardiovasc Surg. 1993;105:435-8.

12. Ho DE, Imak K, King G, Stuart EA. Matching as non parametric preprocessing for reducing model dependence in parametric causal inference. Political Analysis. 2007:15:199-236.

13. Thoemmes F. Propensity score matching in SPSS, 2012. Available at: http:// arxiv.org/abs/1201.6385. Accessed August 4, 2014.

14. Patel ND, Weiss ES, Alejo DE, Nwakanma LU, Williams JA, Dietz HC, et al Aortic root operations for Marfan syndrome: a comparison of the Bentall and valve-sparing procedures. Ann Thorac Surg. 2008;85:2003-14.

15. Stamou SC, Williams ML, Gunn TM, Hagberg RC, Lobdell KW, Kouchoukos NT. Aortic root surgery in the United States: a report from the Society of Thoracic Surgeons database. J Thorac Cardiovasc Surg. 2015;149: 116-22.e4.

16. Kallenbach K, Kojic D, Oezsoez M, Bruckner T, Sandrio S, Arif R, et al Treatment of ascending aortic aneurysms using different surgical techniques: a single-centre experience with 548 patients. Eur J Cardiothorac Surg. 2013;44: 337-45.

17. Lim JY, Kim JB, Jung SH, Choo SJ, Chung CH, Lee JW. Surgical management of aortic root dilatation with advanced aortic regurgitation: Bentall operation versus valve-sparing procedure. Korean J Thorac Cardiovasc Surg. 2012;45:141-7.

18. Franke UF, Isecke A, Nagib R, Breuer M, Wippermann J, Tigges-Limmer K, et al. Quality of life after aortic root surgery: reimplantation technique versus composite replacement. Ann Thorac Surg. 2010;90:1869-75.

19. Badiu CC, Deutsch MA, Sideris C, Krane M, Hettich I, Voss B, et al. Aortic roo replacement: comparison of clinical outcome between different surgical techniques. Eur J Cardiothorac Surg. 2014;46:685-92.

20. Caceres M, Ma Y, Rankin JS, Saha-Chaudhuri P, Englum BR, Gammie JS, et al Mortality characteristics of aortic root surgery in North America. Eur J Cardiothorac Surg. 2014;46:887-93.

21. Etz CD, Girrbach FF, von Aspern K, Battellini R, Dohmen P, Hoyer A, et al. Longevity after aortic root replacement: is the mechanically valved conduit really the gold standard for quinquagenarians? Circulation. 2013;128:S253-62.

22. Lehr EJ, Wang PZ, Oreopoulos A, Kanji H, Norris C, Macarthur R. Midterm outcomes and quality of life of aortic root replacement: mechanical vs. biological conduits. Can J Cardiol. 2011;27:262.e15-20.

23. Coselli JS, Volguina IV, LeMaire SA, Sundt TM, Connolly HM, Stephens EH, et al. Early and 1-year outcomes of aortic root surgery in patients with Marfan syndrome: a prospective, multicenter, comparative study. J Thorac Cardiovasc Surg. 2014;147:1758-66.

24. Kvitting JP, Kari FA, Fischbein MP, Liang DH, Beraud AS, Stephens EH, et al. David valve sparing aortic root replacement: equivalent mid-term outcome for different valve types with or without connective tissue disorder. J Thorac Cardiovasc Surg. 2013;145:117-27.

25. Puskas J, Gerdisch M, Nichols D, Quinn R, Anderson C, Rhenman B, et al Reduced anticoagulation after mechanical aortic valve replacement: interim results from the prospective randomized on- $\mathrm{X}$ valve anticoagulation clinical trial randomized Food and Drug Administration investigational device exemption trial. J Thorac Cardiovasc Surg. 2014;147:1202-10.

Key Words: aorta, prosthesis, surgery, valves 

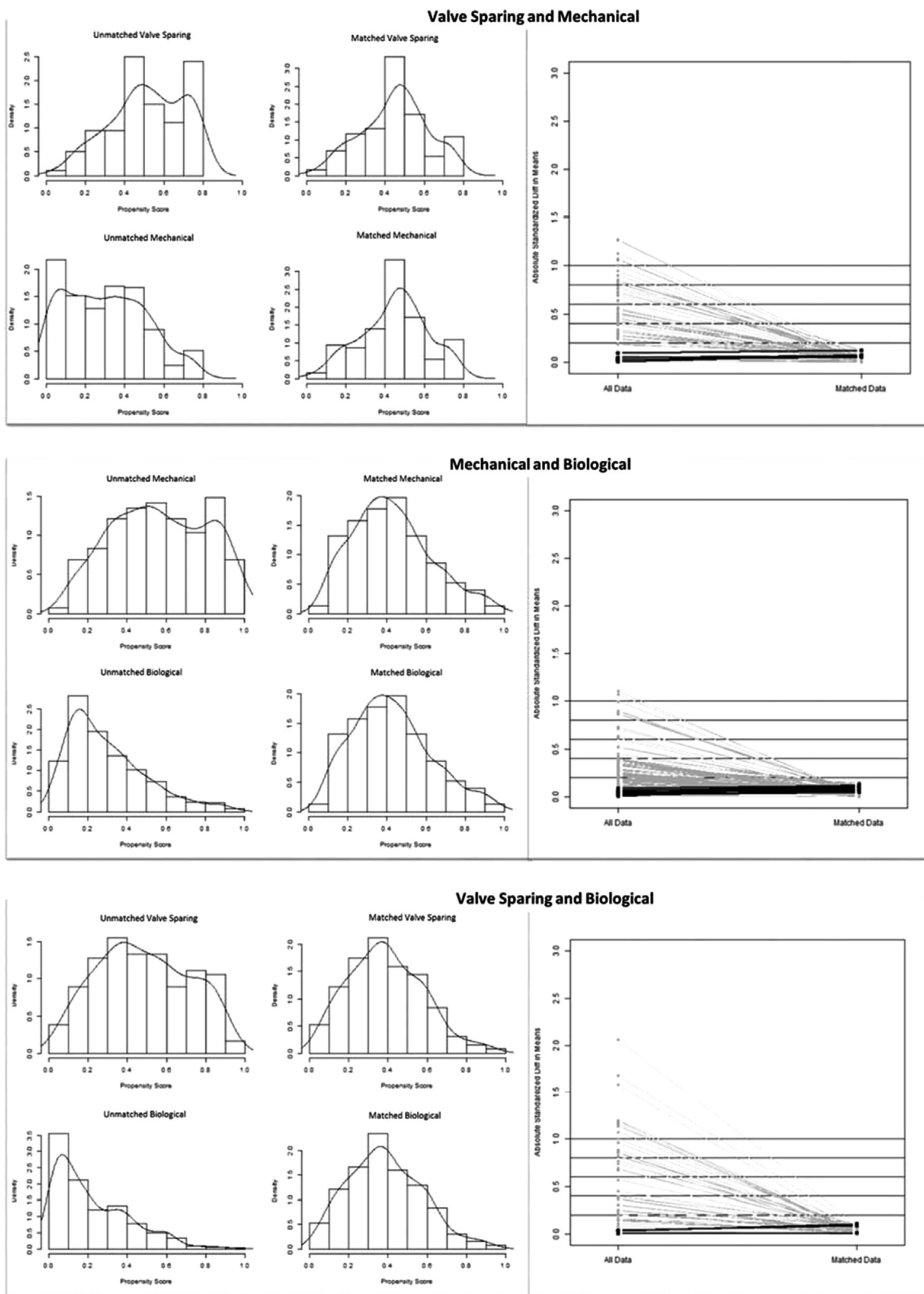

FIGURE E1. Visual balance assessment in PSM models. Propensity score histograms with kernel density estimates for 3 surgical treatments pre- and postmatching. 